\title{
Effects of Urban Forestry on the Local Climate in Cotonou, Benin Republic
}

\author{
Oscar Teka ${ }^{1,}$, , Codjo Euloge Togbe ${ }^{2}$, Rosos Djikpo ${ }^{1}$, Romeo Chabi $^{3}$, Bruno Djossa ${ }^{4}$ \\ ${ }^{1}$ Laboratory of Applied Ecology, Faculty of Agronomic Sciences, University of Abomey-Calavi, Abomey-Calavi, Benin \\ ${ }^{2}$ Laboratory of Plant Biology, Faculty of Agronomic Sciences, University of Abomey-Calavi, Abomey-Calavi, Benin \\ ${ }^{3}$ Laboratory of Biogeography, Department of Geography and Land Planning, Faculty of Arts and Human Sciences, University of Abomey- \\ Calavi, Abomey-Calavi, Benin \\ ${ }^{4}$ High School of Forestry and Wood Engineering, National University of Porto-Novo, Porto-Novo, Benin
}

\section{Email address:}

oscar_teka@yahoo.fr (O. Teka), euloge.togbe@yahoo.fr (C. E. Togbe),djikporosos@gmail.com (R. Djikpo), chabiromeo@yahoo.fr (R. Chabi),djossabruno@gmail.com (B. Djossa)

${ }^{*}$ Corresponding author

\section{To cite this article:}

Oscar Teka, Codjo Euloge Togbe, Rosos Djikpo, Romeo Chabi, Bruno Djossa. Effects of Urban Forestry on the Local Climate in Cotonou, Benin Republic. Agriculture, Forestry and Fisheries. Vol. 6, No. 4, 2017, pp. 123-129. doi: 10.11648/j.aff.20170604.13

Received: May 12, 2017; Accepted: May 24, 2017; Published: July 10, 2017

\begin{abstract}
The effect of urban green on meteorological parameters such as temperature and relative humidity was assessed on one major city street in Cotonou called "Boulevard de Missèbo-Zongo" (BMZ). Tree inventory and field measurement of meteorological parameters were performed on the roadside and central median of the BMZ. Dendrometric data collected were the number of tree species, the number of tree individuals per species, the diameter of trees at breast height, the tree heights, the tree crown shape, shade form on the ground when the sun is at Zenith; while the meteorological data were the air temperature and the relative humidity inside and outside of urban green at 1.5, 2 and 3 meters height measured from $7 \mathrm{am}$ to $6 \mathrm{pm}$ at one hour interval. Data were analyzed using Mixed Generalized Linear Model under R 3.3.1 software. Results showed that street alignment trees were poorly diversified and dominated by Khaya senegalensis. This species appeared to be highly pruned and threatened because of its numerous medicinal virtues. Moreover it was found that air temperature and relative humidity were influenced by the time and the place of measurement. The coolness effect of urban green was evidenced by the decrease in temperature under alignment trees compared with that recorded on roadside free of trees. These results suggested that urban green could be adopted as adaptation strategy to address the issue of global warming in the city.
\end{abstract}

Keywords: Alignment Plantation, Dendrometric Characterization, Meteorological Parameter, Tree Diversity

\section{Introduction}

Nowadays, the benefits of urban forests have been recognized nationally and internationally in the face of the global warming and rapid world population growth $[1,2,3]$. Cities are known worldwide to provide several functions: touristic, historic, agricultural and economic. They facilitate the need of society through exchanges of goods and services. Cities also represent the place from which the government establishes control over the territory [4]. Most cities concentrate public institutions, facilities and economic, mainly tertiary activities. Major cities in the world are nowadays subject to demographic growth concerns. Instances of those cities are New York, Mexico, Chicago, Toronto in North America, Cairo, Tunis, Casablanca and Algiers in North Africa. Cities like Accra, Nairobi, Dakar, Abuja and Cotonou in Sub-Saharan Africa are also facing demographic growth issues such as congestion of urban traffic and pollution of the environment in and around urban areas. To address this rapid demographic growth challenges FAO has developed the concept of "urban forestry" [5] suggesting that cities must remain resilient to the effects of climate change. The process of climate change is likely to increase or decrease extreme temperatures and precipitation patterns 
depending on local conditions, with an impact on the frequency, intensity and location of floods or other climaterelated disasters $[4,6]$. There is an urgent need to mitigate the harmful effects of climate change. The establishment of green spaces appears to be one solution to circumvent these effects. In fact green spaces have several benefits for humans. Among others, urban green provide soothing virtues, improve the quality of the living environment and ensure an ecological and landscape benefits. Moreover, urban green provides beauty, shade and freshness in the surrounding environment, renews the oxygen of the air and regulates the hygrometry $[7,8,9,10]$. Trees remove $\mathrm{CO}_{2}$ from the atmosphere, the most common greenhouse gas, through the process of photosynthesis [12]. Trees also moderate local climate with the advantages of reducing energy costs for residents $[1,13]$. Some plant species fix heavy metals and retain dust in their epidermal leaf hairs [14]. Urban forests can serve as a living laboratory for environmental education in cities [15], and provide income for the municipality through ecotourism. Many other health related benefits have been associated to urban forest such as asthma relief, improved academic performance, and shorter recovery times for patients [16, 17, 18]. In addition, environmental, social, and economic benefits can also be drawn from urban trees $[10,19,20]$.

In Benin, the urbanization rate galloped from $11 \%$ in 1960 to $40 \%$ in 1990 and $42 \%$ in 2005 [21]. Recent projections indicated more than half the population of Benin will live in cities by 2025 bringing urban population to 56,2\% [15]. Although cities and their population constitute a real opportunity for development (e.g. Cotonou contributes to $57 \%$ of urban GDP and $33 \%$ of national GDP) [21], they also generate costs for the environment and public health. Population growth rises from $3 \%$ to $3.2 \%$ per year [21] and worsens the issues of sanitation, pollution and congestion in public spaces. Air pollution mainly occurs through the discharge of smoke into the atmosphere by taxi-motorcycles transportation system (locally called "Zemidjan"), the proliferation of two stroke engines and the use of adulterated fuel etc. Air pollution appears nowadays in Cotonou as a public health problem due to induced problems such as eyes irritation, myocardial infarction and lung disease. The quality of life in urban areas will depend mainly on the size and quality of established green spaces. Due to the rapid degradation of living environment, the need arises to reverse the issues of pollution as well as to mitigate climate change effects. To this end, it is necessary to assess the possible impacts of urban green on the micro-climate in Cotonou. This study assessed the contribution of roadside trees on the softening of the local climate in Cotonou. Specifically, the study focused on dendrometric characterization of the alignment plantations, determining changes in meteorological parameters (temperature and relative humidity) along a vertical gradient and the effects of roadside trees on the microclimate. For this purpose, the following hypothesis was formulated "the alignment trees have significant positive effect on the local climate".

\section{Study Area}

Cotonou is located between $6^{\circ} 21^{\prime}$ and $6^{\circ} 24^{\prime}$ North latitude and $2^{\circ} 22^{\prime}$ and $2^{\circ} 29^{\prime}$ East longitude in the south of Benin. The soil in Cotonou is mostly sandy, with clay or organic components in some places. The water table is very shallow sometimes at less than one meter depth. Cotonou falls in subequatorial climate, characterized by two rainy seasons (mid-March to July; mid-September to October) and two dry seasons (mid-November to March and August to midSeptember).The mean annual temperature in the shade is about $38^{\circ} \mathrm{C}$. The mean annual rainfall is $1300.2 \mathrm{~mm}$ (calculated over the period 1985-2015 using meteorological data from Agence pour la Sécurité de la Navigation Aérienne (ASECNA) Cotonou). This makes it one of the favorable cities to forestry in Benin. Roadside tree species include Khaya senegalensis (Desr.) A. Juss., Terminalia catappa L., Terminalia mantaly H. Perrier and Roystonia regia Kunth.

\section{Materials and Method}

\subsection{Materials}

Tools used for dendrometric and meteorological data collection are the followings: (a) Penta decameter for plot delimitation; (b) Ribbon $\pi$ for the measurement of trees diameters at breast height; (c) Clinometer SUNNTO for tree height measurement; (d) Thermo-hygrometer for measurement of air temperature and relative humidity.

\subsection{Sampling and Data Collection}

Data were collected at the BMZ in the city center. This Boulevard was selected due to the variability of the road trees' species. In addition, it is a commercial place with several companies. An exploratory study was conducted followed by a systematic inventory of all trees on the central median. Data related to the crown shape, shade form on the ground, diameter at beast height ( $\mathrm{dbh}$ ) and crown diameter were collected. Tree species were also identified based on a botanical identification key [22]; and meteorological data (temperature and relative humidity) were collected both on the roadside and in the central median. Data were recorded each one-hour interval from $7 \mathrm{am}$ to $6 \mathrm{pm}$ at three altitudes $(1.5 \mathrm{~m}, 2 \mathrm{~m}$ and $3 \mathrm{~m})$. Meteorological data were collected every 10 days from the 01 November to the 21 December 2016.

\subsection{Data Analysis}

Several methods were used to characterize alignment tree individuals and to evaluate the meteorological parameters variations on the sampled Boulevard.

Statistical analysis using mixed generalized linear model (MGLM) was performed with meteorological parameters (temperature and relative humidity). The choice of MGLM was justified by the fact that data were not normally distributed. This analysis was carried out using $\mathrm{R}$ version 3.3.1. 
Plant diversity was analyzed through species richness $\mathrm{S}$, Shannon diversity index $\mathrm{H}$ and Pielou equitability $\mathrm{R}$ while dendrometric and plant community structure were characterized using linear density $\mathrm{Ni}$, mortality rate $\mathrm{Tm}$, total basal area Gt, linear basal area Gi, quadratic diameter $\mathrm{Dg}$, mean height $\mathrm{Hg}$, shading index $\mathrm{I} 0$, risk index or real fall index IRr, crown shape ratio $\mathrm{Ch}$.

Species richness $(S)$ is the total number of species.

Shannon diversity index ( $H$, in bits) varies from 0 to 5 .

$$
H=-\sum p i \log _{2} p i
$$

$p i$ is the relative proportion of the number of a species $i$ in the set of individuals of all species;

$$
p i=n i / \sum n i
$$

$n i$ is the number of a species $i$ and $\Sigma n i$ the total number of individuals of all species.

Pielou equitability $(R)$ reflects the stability of forest stand, and is the ratio of the current diversity $(H)$ and the maximum theoretical diversity (Hmax) to reach by the plant community.

$$
R=H / H \max =H / \log _{2} S
$$

Pielou equitability varies between 0 and 1 . It tends to 0 when nearly all the forest stand is composed of a single species and to 1 when each species is represented by almost the same number of individuals.

Linear density $(\mathrm{Ni}$, in rods $/ 100 \mathrm{~m})$ is the average number of trees $\mathrm{dbh} \geq 10 \mathrm{~cm}$ over a distance of $100 \mathrm{~m}$.

$$
\mathrm{Ni}=\mathrm{n}_{\mathrm{i}} \mathrm{x} 100 / \mathrm{dt}
$$

$n i$ is the total number of trees in the central median and $d t$, the total distance of central median.

Mortality rate ( $T m$, in \%) is the ratio of the number of dead trees $(\mathrm{m})$ by the total number of trees $n_{t}$ in the central median.

$$
\mathrm{Tm}=\mathrm{m} / \mathrm{n}_{\mathrm{t}}
$$

Total basal area $\left(G_{t}\right.$, in $\left.\mathrm{m}^{2}\right)$ is the sum of the cross section of all trees $\mathrm{dbh} \geq 10 \mathrm{~cm}$ at breast height $(1.3 \mathrm{~m})$, on the entire road.

$$
G_{t}=\frac{\pi}{4} \sum_{i=1}^{n} d_{i}^{2}
$$

$d_{i}$ is the diameter in meter of the tree $i$.

Linear basal area $\left(G i\right.$, in $\left.\mathrm{m}^{2} / 100 \mathrm{~m}\right)$ is the sum of the cross section of all trees $\mathrm{dbh} \geq 10 \mathrm{~cm}$ at breast height $(1.3 \mathrm{~m})$ over a distance of $100 \mathrm{~m}$.

$$
G i=100 \times G_{t} / d t
$$

Quadratic diameter $(D g$, in $\mathrm{cm})$ is the measure of average tree diameter conventionally used in forestry.

$$
D_{g}=\sqrt{\frac{1}{n} \sum_{i=1}^{n} d_{i}^{2}}
$$

$n$ is the number of $\mathrm{dbh} \geq 10 \mathrm{~cm}$ tree on the central median and $d_{i}$, the diameter of tree $i$.

Average height $\left(H_{g}\right.$, in $\left.\mathrm{m}\right)$ is the arithmetic average height of all trees $\mathrm{dbh} \geq 10 \mathrm{~cm}$, on the central median.

$$
H_{g}=\sum H_{i} / n
$$

$H_{i}$ is the height in meter of the tree $i$.

Shading index $\left(I_{0}\right.$, in $\left.\%\right)$ is the coverage rate of green space by shade trees. It varies depending on the inclination of the solar rays and is determined by the crown area of the trees on the ground.

$$
I_{0}=\sum A t \times 100 / A t
$$

Risk index or real fall index $\left(I R_{r}\right.$, in \%) is the ratio of the number of annual falls (by accident or not) recorded by the total number of trees sampled on the central median.

$$
I R_{r}=n_{c} \times 100 / \sum n i
$$

$\mathrm{n}_{\mathrm{c}}$ the number of annual falls recorded and $\Sigma \boldsymbol{n} \boldsymbol{i}$ the total number tree on the central median.

$$
\begin{gathered}
\text { Crown shape ratio }(\mathrm{Ch}, \text { in \%) } \\
\mathrm{C}_{\mathrm{h} \text { normal }}=\mathrm{n}_{\mathrm{i} \text { normal }} \times 100 / \sum \mathrm{n}_{\mathrm{i}} \\
\mathrm{C}_{\mathrm{h} \text { flag }}=\mathrm{n}_{\mathrm{i} \text { flag }} \times 100 / \sum \mathrm{n}_{\mathrm{i}} \\
\mathrm{C}_{\mathrm{h} \text { degraded }}=\mathrm{n}_{\mathrm{i} \text { degraded }} \times 100 / \sum \mathrm{n}_{\mathrm{i}}
\end{gathered}
$$

$\sum \mathrm{n}_{\mathrm{i}}$ total number of trees on the central median of the Boulevard.

\section{Results}

\subsection{Dendrometric Parameters}

The floristic inventory on the alignment trees of the BMZ reported a total of 53 plants belonging to 4 species and 3 families. Meliaceae was the most represented family followed by Combretaceae and Arecaceae. Shannon Diversity Index and Pielou Equitability value were respectively 0.4 bit and 0.2 . This indicated a weak diversity of tree species on the BMZ. Alignment plantation on roadside of BMZ was strongly dominated by one species, $K$. senegalensis. The linear density on the BMZ was six (06) trees within $100 \mathrm{~m}$ distance while the average diameter of the sampled trees was $31.6 \mathrm{~cm}$. The average height of the trees was $10.52 \mathrm{~m}$ while the shading index was estimated at $55.58 \%$. The potential risk index and the real fall index were respectively $15.09 \%$ and $5.66 \%$ for 2016 . Crown shape ratio for normal, flag and degraded shapes were respectively estimated at $96.23 \%, 1.89 \%$ and $1.88 \%$. 
This distribution pattern showed that young individuals $(15<\mathrm{dbh} \leq 30 \mathrm{~cm})$ were most represented than "old" individuals $(30<\mathrm{dbh} \leq 65 \mathrm{~cm})$ (Figure 1). The distribution trend also fall in a "J" reverse pattern usually reported in forest as viable population because the recruitment of the population is functioning.

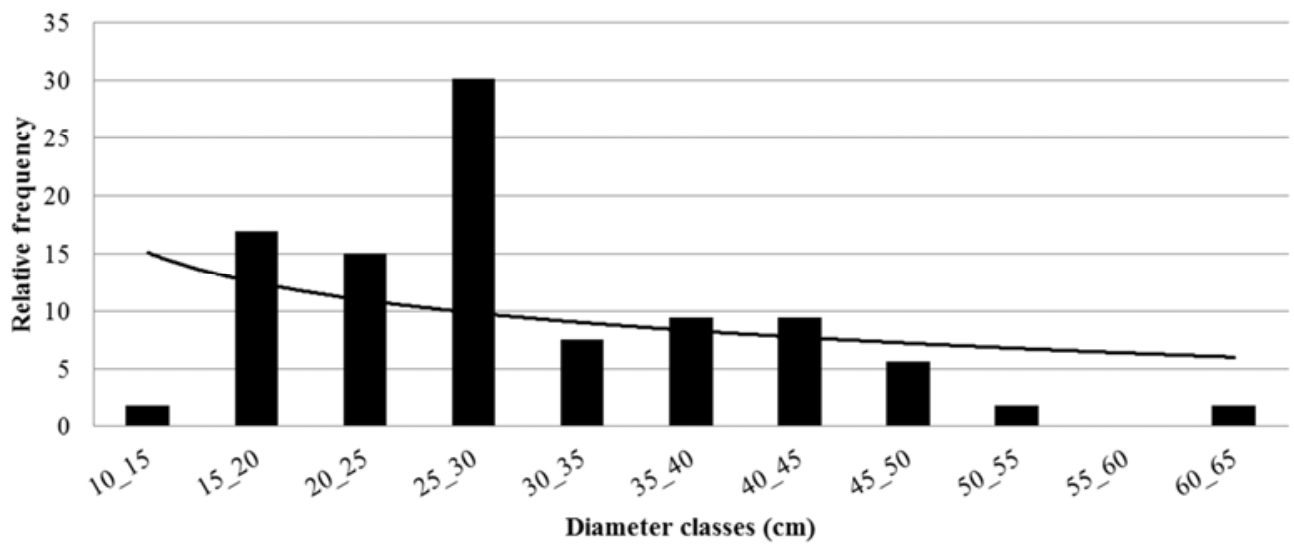

Figure 1. Alignment tree individuals' distribution in diameter classes.

\subsection{Meteorological Parameters}

Data collected on temperature and relative humidity at selected altitudes and sites (in and outside of urban green) showed an increase in temperature from 7 am to $1 \mathrm{pm}$ and a

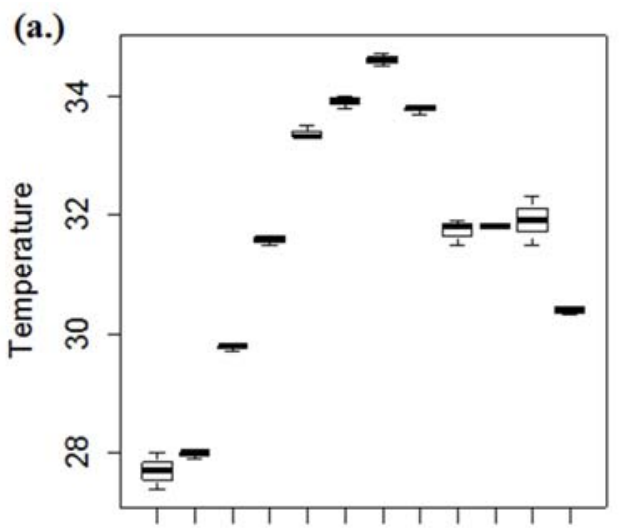

$07 \mathrm{~h}$ coh 11h $13 \mathrm{~h} \quad 15 \mathrm{~h} \quad 17 \mathrm{~h}$

(c.)

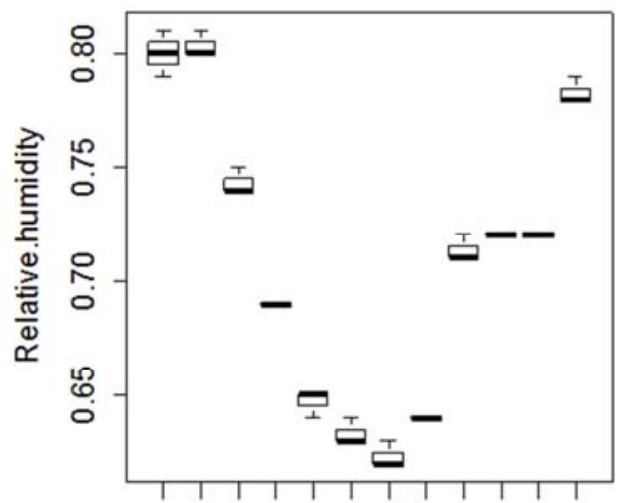

$07 \mathrm{~h}$ coh $11 \mathrm{~h}$ 13h $15 \mathrm{~h} \quad 17 \mathrm{~h}$ decrease from $1 \mathrm{pm}$ to $6 \mathrm{pm}$ (Figure $2 \mathrm{a}$ and $2 \mathrm{~b}$ ). The relative humidity (Figures 2c and 2d) showed an opposite pattern. In fact the relative humidity decreased from 7 am to $1 \mathrm{pm}$ and started ascending and ended up at $6 \mathrm{pm}$.

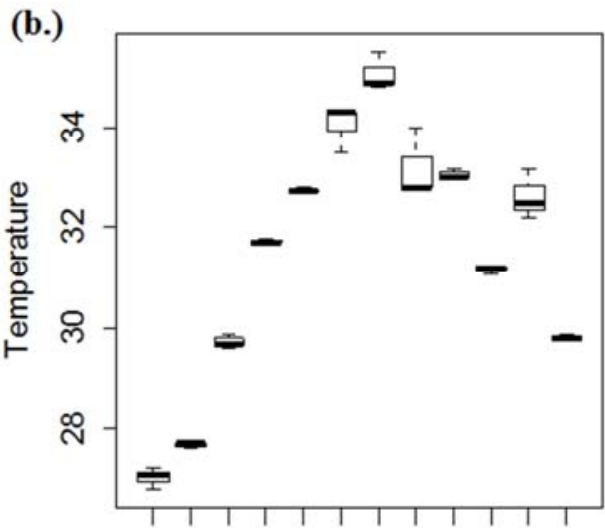

$07 \mathrm{~h} @ 11 \mathrm{~h} 13 \mathrm{~h} \quad 15 \mathrm{~h} \quad 17 \mathrm{~h}$

D-time(Hor)

(d.)

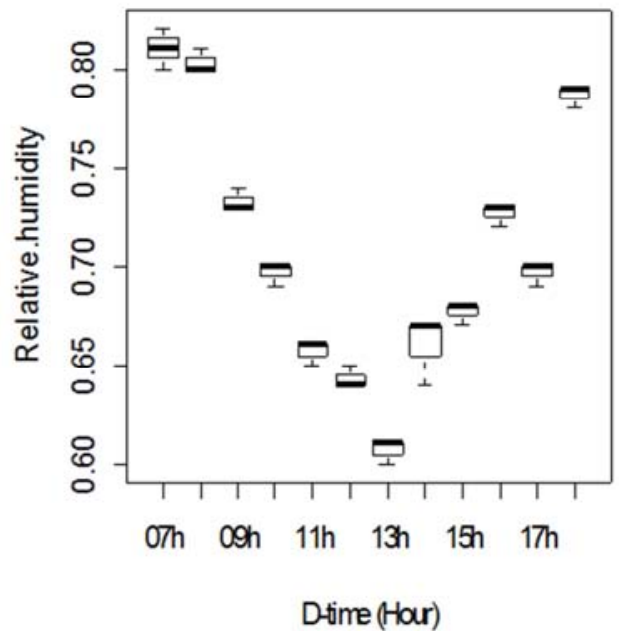

Figure 2. Global mean trends of temperature $(a \& b)$ and relative humidity $(c \& d)$ in day time in and outside the alignment trees. 
The interaction of site and altitude had significant effect results (Table 1 with Mixed Effects on temperature). On the other side, relative humidity increased significantly $(\operatorname{Pr}<0.05)$
$(\operatorname{Pr}<0.05)$ on the temperature as shown by the MGL from outside the alignment trees to inside the central median green (Table 1 with Mixed Effects on relative humidity).

Table 1. Generalized Linear Model with mixed effects.

\begin{tabular}{llll}
\hline & Chisq & Df & Pr (>Chisq) \\
\hline A: on temperature & & & \\
Site & 0.00 & 1 & 0.95 \\
Altitude & 2.63 & 2 & 0.26 \\
Site: Altitude & 9.15 & 2 & $0.01 *$ \\
B: on relative humidity & & & $0.04 *$ \\
Site & 3.96 & 1 & 0.11 \\
Altitude & 4.30 & 2 & $<2.2 \mathrm{e}-16 * * *$ \\
D-time & 21206.94 & 11 & $0.01 *$ \\
Site: Altitude & 8.62 & 2 & $<2.2 \mathrm{e}-16 * * *$ \\
Site: D-time & 346.45 & 11 & $2.29 \mathrm{e}-10 * * *$ \\
Altitude: D-time & 91.02 & 22 & \\
\hline
\end{tabular}

Df: Degree of freedom, Pr: Probability test, Significant codes: 0 ‘***’ 0.001 ‘**’ 0.01 ‘*’ 0.05 ‘’ 0.1

\section{Discussion}

\subsection{Poor Biological Diversity and Cares}

Species richness (4 species) and Shannon diversity index ( 0.4 bits) provide evidence of a poor diversity of tree species along the BMZ, reflecting that the number of tree species selected for street alignment plantation was limited and usually oriented toward shade and ecological comfort insurance.

$K$. senegalensis species is targeted for its medicinal virtues. In fact this plant is used by local communities as remedy for 41 diseases; and for this purpose $K$. senegalensis species are seriously barked showing curved stems at roadside and central median of BMZ. $K$. senegalensis bark is also involved in the healing of gynecological affections [23, 24]. The fact that those communities living in these neighborhoods mainly had a low purchase power constrained them to use this species to cure their diseases. As far as the leaves are concerned, they were used as feed for home livestock. This justifies the high pressure of pruning exerted on the species. This harvest pattern could compromise the survival and regeneration of this species. Therefore, a trade-off should be envisioned between the functions of tree species, the social status of local communities and their knowledge regarding the virtues the species carries; especially in the context of Benin Republic (developing country). The multidisciplinary approach that brings together actors from various backgrounds (ethno-botanic, traditional pharmacopoeia and sociology) is therefore required in the implementation of urban green initiatives. In terms of growth speed, $K$. senegalensis does not rank higher. In order to prevent this species from extinction, a special care has been provided to it by urban forest administration which endeavors to reinforce $K$. senegalensis stand every year.

The three remaining species were not subject to the same pressure compared with $K$. senegalensis that dominated the
BMZ. The high dominance of $K$. senegalensis was evidenced by the value of Pielou equitability (0.2). Values of risk index $(15.09 \%)$ and real fall index $(5.66 \%)$ was mainly the result of the three remaining species that lacked the same care provided to $K$. senegalensis.

\subsection{Coolness Effect of Urban Forests}

It was observed that the air temperature and relative humidity varied as a function of Site*Altitude combination. It was also found that temperature and relative humidity varied during the day time in both sides (central median and roadside). Variation of meteorological parameters along the day is translated through the fact that when the air temperature increases, the relative humidity decreases and vice versa. The decrease in temperature observed with data collected in central median compared to that of roadside could be explained by the difference in albedo between the alignment plantation and the roads. Indeed, the pavements are made of materials (asphalt and concrete) which have a low reflexive capacity compared to the plantation. The more a material reflects the sun's radiation, the less it absorbs solar energy and the less it warms up. The coolness resulted then from the effect of crown shape (vegetation cover) on this meteorological parameter. In fact the coolness effect of crown shape on the temperature was determined by water evaporation from the leaves which led to the increase in the relative humidity. This created a micro-climate around the tree foliage. Indeed, the foliage of trees shields solar radiation and cools the air through evaporation and shade on the ground, and on the walls. It had been recognized that in certain conditions, trees reduce the radiation and slow down the wind speed $[25,26,27]$. The coolness of the crown shape was reinforced by the relatively high shading index (55.58\%) obtained with the urban green, which implies a low permeability to light and solar radiation. Because of dominance of $K$. senegalensis along the BMZ, it could be hypothesized that the contribution of this species to the overall coolness of the atmosphere was higher than that of the other species. This is an important observation that calls 
for further research on the relative contribution of each species to environment coolness in urban green.

Differences observed in temperature and relative humidity with regard to the altitudes $(1.5,2,3 \mathrm{~m})$ at both central median and roadside were significant. These variations could be partially explained by the observed changes in temperature with height in the troposphere known as the Environmental Lapse Rate (ELR) [28].

Considering the effect of wind on the temperature, Rodriguez-Potes [29] distinguished three situations. Firstly, in the case of punctual solar radiation and low air speed, the air temperature will be high. Secondly, the temperature will be moderate when the solar radiation is reduced and accompanied with an increasing air speed. Thirdly, the air temperature will be in between when the solar radiation is diffused followed by a penetration of the wind flow. It therefore appears that the shading index on a street impacts on air temperature.

Plantation with high shading index may increase the temperatures if trees become obstacles to wind flow that could eventually cool convective environments. Thus, in order to ensure a cool planted street, priority should be given to plantations which offer high vegetation cover and provide shade to the street and the buildings, but with sufficient separation to allow the wind to circulate. It appears that apart from trees, urban architecture especially the orientation of the streets impact air temperature in one direction or another [29, $30,31]$. That is the reason why better results will be obtained if a real trade-off is found between the form of construction of cities and the street plantation.

\section{Conclusion}

It came out from this study that the alignment plantation in Cotonou was characterized by low plant diversity and that this plantation was subject to anarchic exploitation which consisted of debarking and pruning of $K$. senegalensis individuals. This indicated the lack of care and effort from municipal authorities to manage green spaces which jeopardizes the viability of alignment trees in the city. The high pressure exerted on $K$. senegalensis was due to its virtues in traditional medicine in Benin linked to the fact that the species was known to be a remedy of about forty human diseases and affections. This study also allowed concluding that urban green plays an important role in cooling the environment in the city because trees' crown restricts the penetration of solar radiation and luminosity. They are also exchanges medium of water with the ambient environment. This interaction with the environment increases the relative humidity while lowering the air temperature. Based on these attributes, alignment plantations can be recommended to make savings in domestic energy use in cities. The beneficial effects of alignment plantations on the micro-climate can also be enhanced by optimizing the position of trees to the roadway and to the buildings which determines the air velocity, important factor in regulating the air temperature and the relative humidity. In the quest of optimization of the beneficial effects, the architecture and orientation of housing are critical factors to be considered. In fact, urban architecture especially the orientation of the streets impact on air temperature in one direction or another. That is the reason why better results will be obtained if a real trade-off is found between the form of construction of cities and the street plantation. This calls for a synergistic effort from scholars from various backgrounds to ensure the sustainability of any program addressing urban forestry and urban greening. Given the important role of the urban green in carbon sequestration and mitigation of the adverse effects of climate change, there is a need for immediate actions (sensitization of local communities) to safeguard and strengthen the alignment plantations.

\section{References}

[1] Kim, S.-H., Chung, U. L., Joshua L. \& Anderson, R. E. (2012). Assessing the Impacts of Climate Change on Urban Forests in the Puget Sound region: Climate Sustainability for Tree Species. School of Environmental and Forest Sciences, College of the Environment, University of Washington.

[2] Chow, W. T. L., Nur, S., Binte, A., Akbar, A., Li, S., \& Roth, M. (2016). Assessment of measured and perceived microclimates within a tropical urban forest. Urban Forestry \& Urban Greening, 16, 62-75. http://doi.org/10.1016/j.ufug. 2016.01.010.

[3] Hsieh, C-M. \& Jan Zhang, L. (2016). A simplified assessment of how tree allocation, wind environment, and shading affect human comfort. Urban For. Urban Green. 18, 126-137.

[4] Kadir, M. A. A. \& Orthman, N. (2012). Towards a better tomorrow: street trees and their values in urban areas. Procedia-Social and Behavioral Sciences, 35, 267-274.

[5] FAO. (2012). La foresterie urbaine et périurbaine.

[6] IPCC. (2011). Mitigation, Climate change. IPCC special report on renewable energy sources and climate change mitigation.

[7] Clark, J. R., Matheny, N. P., Cross, G. \& Wake, V., (1997). A Model of Urban Forest Sustainability. Journal of Arboriculture. 23, 17-30.

[8] McPherson, E. \& Simpson, J. R. (2003). Potential energy savings in buildings by an urban tree planting programme in California. Urban Forestry \& Urban Greening 2; 073-086.

[9] Lopez, F. \& Roussel, J. M. (2010). Encombrement des trottoirs: Les espaces verts. Une voirie pour tous. Fiche $n^{\circ} 3.5$. $10 \mathrm{p}$.

[10] Kenney, W. A., van Wasseanaer, P. J. E. \& Satel, A. L. (2011). Criteria and Indicators for Strategic Urban Forest Planning and Management. Arboriculture \& Urban Forestry. 37, 108-117.

[11] Abreu-Harbich, L.V., Labaki, L.C. \& Matzarakis, A. (2015). Effect of tree planting design and tree species on human thermal comfort in the tropic. Landscape and Urban Planning 138, 99-109.

[12] FAO. (2000). La foresterie urbaine en Amérique du nord et ses interactions au niveau mondial. NAFC/8. 
[13] Vaz, M., Doick, K. J., Handley, P. \& Peace, A. (2016). The impact of greenspace size on the extent of local nocturnal air temperature cooling in London. Urban Forestry \& Urban Greening, 16, 160-169.

http://doi.org/10.1016/j.ufug.2016.02.008.

[14] Bory, G. (2000). L'arbre dans la ville. On ne regarde pas les arbres en ville ! Dossier foret. Fiche extraite du Dossier Forêt.170p.

[15] FAO. (2011). Situation des forêts du monde. Rome, Italie. $176 \mathrm{p}$.

[16] Poe, M. R., McLain, R. J., Emery, M. \& Hurley, P. T. (2013). Urban forest justice and the rights to wild foods, medicines, and materials in the city. Human Ecology, 41(3), 409-422.

[17] Sanesi, G., Gallis, C., \& Kasperidus, H. D. (2015). Urban Forests and Their Ecosystem Services in Relation to Human Health. In K. Nilsson, M. Sangster, C. Gallis, T. Hartig, S. vries De, K. Seeland, \& J. Schipperijn (Eds.), Forests, Trees and Human Health (pp. 23-40). Springer.

[18] Akpinar, A. (2016). Urban Forestry \& Urban Greening How is quality of urban green spaces associated with physical activity and health? Urban Forestry \& Urban Greening, 16, 76-83. http://doi.org/10.1016/j.ufug.2016.01.011.

[19] Shackleton, S., Chinyimba, A., Hebinck, P., Shackleton, C. \& Kaoma, H. (2015). Landscape and Urban Planning Multiple benefits and values of trees in urban landscapes in two towns in northern South Africa. Landscape and Urban Planning, 136, 76-86. http://doi.org/10.1016/j.landurbplan.2014.12.004.

[20] Kim, G., Miller, P. A., \& Nowak, D. J. (2015). Assessing urban vacant land ecosystem services: Urban vacant land as green infrastructure in the City of Roanoke, Virginia. Urban Forestry \& Urban Greening, 14 (3), 519-526. http://doi.org/10.1016/j.ufug.2015.05.003.

[21] INSAE/RGPH4. (2013). Quatrième Recensement Général de la Population et de l'Habitation: Que retenir des effectifs de population en 2013 ? Cotonou, Bénin, 35 p.
[22] Akoègninou, A., Van der Burg, W. J. \& Van der Maesen, L. J. G. (2006). Flore analytique du Bénin (No. 06.2). Backhuys Publishers.

[23] Ouinsavi, C. (2000). In situ conservation of Khaya senegalensis (Desr.) A. Juss: socio-economic relevance, structure and dynamic of natural communities and Productivity of trial plantations in Benin. Engineer Agronomist Thesis, FSA/UAC, Abomey-Calavi, Benin, 120 p.

[24] Sokpon, N. \& Ouinsavi, C. (2004). Gestion des plantations de Khaya senegalensis au Bénin. Bois et Forêts des Tropiques, $\mathrm{n}^{\circ}$ 279 (1) 37.

[25] Stewart, I. D. \& Oke, T. (2009). Classifying urban climate field sites by "local climate zones": The case of Nagano, Japan. In: Seventh International Conference on Urban Climate (Vol. 29).

[26] Feyisa, G. L., Dons, K. \& Meilby, H. (2014). Efficiency of parks in mitigating urban heat island effect: An example from Addis Ababa. Landscape and Urban Planning 123, 87-95.

[27] Gromke, C., Blocken, B., Janssen, W., Merema, B., van Hooff, T. \& Timmermans, H. (2015). CFD analysis of transpirational cooling by vegetation: Case study for specific meteorological conditions during a heat wave in Arnhem, Netherlands. Building and Environment 83, 11-26.

[28] Arya, S. P. (1999). Air pollution meteorology and dispersion (Vol. 6). New York: Oxford University Press.

[29] Rodriguez Potes, L. M., Hanrot, S., Dabat, M. A. \& Izard J. L. (2012). 2nd International Congress on Ambiances, Montreal.

[30] Panagopoulos, T. (2008). Using microclimatic landscape design to create thermal comfort and energy efficiency. Actas da 1st Conferência sobre Edificios Eficientes, Universidade di Algarve, 25 de Janeiro.

[31] Hsieh, C. M., Ni, M. C. \& Tan, H. (2014). Optimal wind environment design for pedestrians in transit-orienteddevelopment planning. Journal of Environment Protection and Ecology 3A, 1385-1392. 